Weidlich, Amanda de Moraes; Schneider, Paulo Henrique. A solidariedade social como instrumento para superação da crise da democracia representativa. Revista Eletrônica Direito e Política, Programa de Pós-Graduação Stricto Sensu em Ciência Jurídica da UNIVALI, Itajaí, v.10, n.4, 30 quadrimestre de 2015. Disponível em: www.univali.br/direitoepolitica - ISSN $1980-7791$.

\title{
A SOLIDARIEDADE SOCIAL COMO INSTRUMENTO PARA SUPERAÇÃO DA CRISE DA DEMOCRACIA REPRESENTATIVA
}

\author{
THE SOCIAL SOLIDARITY AS AN INSTRUMENT FOR OVERCOMING \\ THE CRISIS OF REPRESENTATIVE DEMOCRACY
}

\author{
Amanda de Moraes Weidlich ${ }^{1}$ \\ Paulo Henrique Schneider ${ }^{2}$
}

SUMÁRIO: Introdução; 1. Democracia Representativa: do surgimento à crise; 2. A evolução da concepção de solidariedade; 3 . O resgate da solidariedade social como instrumento para superação da crise da democracia representativa; Considerações Finais; Referências das Fontes Citadas.

\section{RESUMO}

A democracia representativa moderna passa por um momento de intensa crise, resultado das limitações do modelo de representação, do descrédito das instituições democráticas e do recrudescimento do individualismo exacerbado. Dessa forma, empregando-se o método hipotético dedutivo, a partir de um breve apanhado histórico e da identificação e análise dos elementos que levaram a essa crise, sugere-se a valorização da ideia de solidarismo social como meio de possível superação dos conflitos democráticos, a partir do estabelecimento de um novo paradigma ético à democracia, fundado no resgate do sentimento de solidariedade e na constatação da interdependência entre os cidadãos.

PALAVRAS-CHAVE: Democracia representativa; Crise; Solidariedade; Superação.

\footnotetext{
1 Especialista em Direito Civil, Mestranda em Direito pela Faculdade Meridional - IMED, Procuradora do Estado do Rio Grande do Sul. E-mail amanda_weidlich@hotmail.com.

2 Mestre em Direito pela Universidade de Santa Cruz do Sul - UNISC, Especialista em Direito Processual Civil pela Universidade Luterana do Brasil - ULBRA, Especialista em Direito do Trabalho e Previdência Social pela Universidade de Passo Fundo - UPF, professor de Direito do Trabalho da Universidade de Passo Fundo - UPF, Advogado. E-mail phschneider@upf.br.
} 
Weidlich, Amanda de Moraes; Schneider, Paulo Henrique. A solidariedade social como instrumento para superação da crise da democracia representativa. Revista Eletrônica Direito e Política, Programa de Pós-Graduação Stricto Sensu em Ciência Jurídica da UNIVALI, Itajaí, v.10, n.4, 30 quadrimestre de 2015. Disponível em: www.univali.br/direitoepolitica - ISSN $1980-7791$.

\section{ABSTRACT}

Modern representative democracy is going through a time of intense crisis, as a result of the limitations of representation model, the discrediting of democratic institutions and the resurgence of exacerbated individualism. Thus, whith the hypothetical deductive method, from a brief survey history and the identification and analysis of the elements that led to this crisis, it is suggested that the appreciation of the idea of social solidarism as a possible means of overcoming the democratic conflicts, from the establishment of a new paradigm ethical democracy, founded on the rescue of the sense of solidarity and the realization of the interdependence among the citizens.

KEYWORDS: Democracy representative; Crisis; Solidarity; Overcoming.

\section{INTRODUÇÃO}

A tradicional concepção de democracia como poder "do povo e para o povo" passa por um período de intenso questionamento, decorrência da crise do modelo representativo, do descrédito das instituições democráticas e do recrudescimento do individualismo exacerbado.

O que se vê hoje é o alheamento cada vez maior dos cidadãos, que, descrentes de seus representantes, optam por se abster das decisões de interesse do Estado, desvirtuando o ideal democrático de poder "de todos" para poder "de poucos".

A partir dessa constatação, o presente trabalho sugere o resgate da solidariedade social como meio de fortalecer e ressignificar a democracia representativa, mediante o estabelecimento de um novo paradigma ético democrático, fundado nos sentimentos de fraternidade e de interdependência entre os indivíduos que integram uma sociedade.

Sem a pretensão de solucionar os problemas vivenciados pela democracia representativa pós-moderna, as presentes linhas objetivam apenas lançar novos questionamentos sobre o tema e sugerir uma alternativa viável ao fortalecimento das instituições democráticas. 
Weidlich, Amanda de Moraes; Schneider, Paulo Henrique. A solidariedade social como instrumento para superação da crise da democracia representativa. Revista Eletrônica Direito e Política, Programa de Pós-Graduação Stricto Sensu em Ciência Jurídica da UNIVALI, Itajaí, v.10, n.4, 30 quadrimestre de 2015. Disponível em: www.univali.br/direitoepolitica - ISSN $1980-7791$.

\section{DEMOCRACIA REPRESENTATIVA: DO SURGIMENTO À CRISE}

A ideia de democracia não é nova, pelo contrário, remonta a antiguidade Clássica e originou-se na Grécia (demo-kratia), onde o vocábulo denominava os regimes nos quais as decisões eram coletivamente tomadas pelos cidadãos integrantes da polis, e é hoje empregado para designar aqueles governos cujo poder é exercido pelo povo. ${ }^{3}$

Essa ideia de participação política de todos remete ao conceito de zoon politikon de Aristóteles e à polis grega, pois pressupõe a vida em sociedade e a solução dos conflitos mediante a persuasão, ou seja, pela utilização do discurso em substituição à violência, que era restrita à vida fora da polis. ${ }^{4}$

A partir de seu surgimento em Atenas, a democracia passou por três grandes momentos históricos do pensamento político, concernentes às Teorias Clássica, Medieval e Moderna. ${ }^{5}$

De acordo com a Teoria Clássica, a democracia é a forma de governo pela qual o poder é exercido por todos os cidadãos juridicamente assim considerados, contrapondo a monarquia e a aristocracia, regimes nos quais o governo incumbe, respectivamente, a um só e a poucos. A Teoria Medieval, de origem romana, acrescenta o elemento soberania ao poder do povo, que se torna representativo ou é derivado do poder do príncipe. Por fim, a Teoria Moderna, ou Teoria de Maquiavel, distingue as formas básicas de governo: a monarquia e a república, equiparando essa última à democracia. ${ }^{6}$

Conforme visto, a noção de democracia encerra ideias demasiado extensas, que dificultam a construção de um conceito estanque. Entretanto, muitos autores se aventuraram na elaboração de uma definição do que vem a ser um regime democrático, a começar pelo célebre discurso de Gettysburg de

\footnotetext{
${ }^{3}$ BARROSO, José Durão. Democracia. In: POLIS Enciclopédia Verbo da Sociedade e do Estado:Antropologia, Direito, Economia, Ciência Política. São Paulo: Verbo, 1987. v. 2, p. 70.

${ }^{4}$ ARENDT, Hanna. A Condição Humana. São Paulo: Forense Universitária, 1981, p. 34-35.

${ }^{5}$ BOBBIO, Norberto. Dicionário de Política.12. ed. Brasília: UnB, 2004, p.319.

${ }^{6}$ BOBBIO. Dicionário de Política, p. 319.
} 
Weidlich, Amanda de Moraes; Schneider, Paulo Henrique. A solidariedade social como instrumento para superação da crise da democracia representativa. Revista Eletrônica Direito e Política, Programa de Pós-Graduação Stricto Sensu em Ciência Jurídica da UNIVALI, Itajaí, v.10, n.4, 30 quadrimestre de 2015. Disponível em: www.univali.br/direitoepolitica - ISSN $1980-7791$.

Abraham Lincoln, para quem "Democracia é o poder do povo, pelo povo e para o povo". 7

Segundo Juan Linz, apud Barroso ${ }^{8}$,

um regime é democrático quando permite a livre formulação das preferências políticas através do exercício das liberdades básicas de associação, de informação e de comunicação, a fim de estabelecer uma competição livre entre os dirigentes, de modo que se controle regularmente, e por meios pacíficos, o seu direito a governarem.

José Durão Barroso ainda considera possível definir o regime democrático como sendo aquele ${ }^{9}$

em que existe efectiva competição para o exercício do poder político e em que este, normalmente exercido através de mecanismos de representação por via electiva, respeita os princípios de igualdade perante a lei e as liberdades e garantias fundamentais dos cidadãos.

Para Zvetan Todorov, a democracia é "um regime no qual o poder pertence ao povo. Em outras palavras, a população inteira escolhe seus representantes, os quais, de maneira soberana, estabelecem leis e governam o país durante um período de tempo decidido de antemão". ${ }^{10}$

Em comum, observa-se que os conceitos do termo democracia são elaborados a partir da descrição de seus elementos, sendo normalmente

\footnotetext{
7 LINCOLN, Abraham. 0 discurso de Gettysburg. Disponível em <http://www.oabsp.org.br/institucional/grandes-causas/o-discurso-de-gettysburg>. Acesso em 03 fevereiro 2014.

8 BARROSO, José Durão. Democracia. In: Polis Enciclopédia Verbo da Sociedade e do Estado: Antropologia, Direito, Economia, Ciência Política. São Paulo: Verbo, 1987. v. 2, p. 71.

9 BARROSO, José Durão. Democracia p. 72.

${ }^{10}$ TODOROV, Tzvetan. Os inimigos íntimos da democracia. Tradução Joana Angélica d'Avila Melo. São Paulo: Companhia das Letras, 2012, p. 15-16
} 
Weidlich, Amanda de Moraes; Schneider, Paulo Henrique. A solidariedade social como instrumento para superação da crise da democracia representativa. Revista Eletrônica Direito e Política, Programa de Pós-Graduação Stricto Sensu em Ciência Jurídica da UNIVALI, Itajaí, v.10, n.4, 30 quadrimestre de 2015. Disponível em: www.univali.br/direitoepolitica - ISSN $1980-7791$.

identificados os seguintes: 1 ) poder exercido pelo povo; 2) representantes legitimamente eleitos; 3) regras eletivas previamente estabelecidas; 4) observância e respeito aos direitos e garantias fundamentais dos cidadãos; e 5) a existência de uma sociedade livre em que prepondera a influência popular. ${ }^{11}$

Ou seja, o significado descritivo do termo democracia, como governo de todos, não se alterou quando da passagem do pensamento clássico para o pensamento medieval e, posteriormente, para o moderno, restando, entretanto, modificado seu significado valorativo e o modo pelo qual o poder é exercido pelo povo, diretamente, como na democracia dos antigos, ou por meio de representantes legitimamente eleitos, no que se convencionou denominar democracia representativa. ${ }^{12}$

O desenvolvimento imoderado dos Estados tornou (ao menos em linhas gerais) inviável a adoção de um modelo de democracia direta, concebida como aquela em que o poder é exercido diretamente por todos, razão pela qual, na modernidade, as definições acabam sempre por contemplar os elementos da democracia representativa.

Conforme esclarece Bobbio, em um regime democrático representativo, "as deliberações coletivas, isto é, as deliberações que dizem respeito à coletividade inteira, são tomadas não diretamente por aqueles que dela fazem parte mas por pessoas eleitas para essa finalidade". ${ }^{13}$

Disso se constata que a democracia representativa fundamenta-se na ideia de representação política e, portanto, é imprescindível investigar o conteúdo e os poderes dessa representação para delinear os contornos desse modelo de regime democrático.

\footnotetext{
${ }^{11}$ PANIZA, Alexandre de Lima. Democracia e Contratualismo nas concepções de Hobbes e Rousseau: uma abordagem histórica. In: Revista Brasileira de Direito Constitucional. n. 3. São Paulo: Editora Método, 2004, p. 251.

${ }^{12}$ BOBBIO, Norberto. Liberalismo e Democracia. Tradução: Marco Aurélio Nogueira. São Paulo: Brasiliense, 2005, p. 32-33.

${ }^{13}$ BOBBIO, Norberto. O Futuro da Democracia: Uma defesa das regras do jogo. 2. ed. Tradução Marco Aurélio Nogueira. Rio de Janeiro: Paz e Terra, p. 44.
} 
Weidlich, Amanda de Moraes; Schneider, Paulo Henrique. A solidariedade social como instrumento para superação da crise da democracia representativa. Revista Eletrônica Direito e Política, Programa de Pós-Graduação Stricto Sensu em Ciência Jurídica da UNIVALI, Itajaí, v.10, n.4, 30 quadrimestre de 2015. Disponível em: www.univali.br/direitoepolitica - ISSN $1980-7791$.

Ainda segundo Norberto Bobbio, a representação política se dá por meio da eleição de representantes, a quem incumbe a defesa dos interesses gerais dos representados, vislumbrando-se duas características: 1) uma vez eleito, o representante não é mais responsável perante seus eleitores, pois seu mandato não pode ser revogado; 2) por representar os interesses gerais, 0 representante não é responsável diretamente perante seus eleitores. ${ }^{14}$

Todos esses elementos convergem para a formulação de um conceito formal de democracia, mas não incluem o conteúdo ético da definição substancial de regime democrático, qual seja, a igualdade entre os representados.

É precisamente a igualdade entre os cidadãos que possibilita a realização de eleições com um número considerável de eleitores, os quais representam a vontade da maioria $e$, por consequência, atribuem um conteúdo ético e substancial à ideia de governo de todos e para todos.

Não se pretende uma igualdade plena, absolutamente inviável no mundo real onde reina a diversidade, mas sim uma igualdade jurídica, comum a todos pelo simples fato de pertencerem à espécie humana, e que se revela no tratamento isonômico conferido pela lei.

Outro elemento essencial à concepção de um regime político verdadeiramente democrático, é o direito de liberdade, pois sem liberdade de pensamento e de expressão não se cogita do poder do povo.

Muito se discutiu acerca da compatibilidade entre o Estado Liberal e o Regime Democrático, forçoso reconhecer, porém, que a liberdade constitui pressuposto inafastável da Democracia, na medida em que esta pressupõe o poder de escolha (eleição) de seus representantes entre alternativas possíveis. Não é por outra razão que Bobbio considera a democracia o "natural desenvolvimento do Estado Liberal". ${ }^{15}$

Ocorre que malgrado os êxitos colhidos na era Moderna, a democracia representativa enfrenta um momento de inegável crise, seja porque houve

\footnotetext{
${ }^{14}$ BOBBIO, Norberto. O Futuro da Democracia, p. 47.

${ }^{15}$ BOBBIO, Norberto. Liberalismo e Democracia, p. 32-33.
} 
Weidlich, Amanda de Moraes; Schneider, Paulo Henrique. A solidariedade social como instrumento para superação da crise da democracia representativa. Revista Eletrônica Direito e Política, Programa de Pós-Graduação Stricto Sensu em Ciência Jurídica da UNIVALI, Itajaí, v.10, n.4, 30 quadrimestre de 2015. Disponível em: www.univali.br/direitoepolitica - ISSN $1980-7791$.

o desvirtuamento de seus elementos constitutivos, seja porque descumpridas as promessas do ideário democrático.

Com efeito, o que se verifica, hoje, é a existência de "políticos profissionais", verdadeiros atores de showbusiness, mais imbuídos do patrocínio de seus próprios interesses, que da representação geral do povo. Ou seja, atualmente, são raras as hipóteses em que os interesses privados são relegados em favor de uma noção de coletividade, fenômeno que JeanMarie Guéhenno denominou de "engarrafamento político" (political gridlock $)^{16}$, pois se assemelha a um congestionamento de trânsito, no qual cada motorista acredita que o outro está prejudicando o fluxo, quando na verdade todos contribuem para a obstrução da via.

A soberania popular também é ameaçada pela motivação espúria dos eleitores, que não raro comparecem à votação objetivando alcançar as benesses prometidas pelos "políticos profissionais", deixando de lado os interesses gerais que deveriam nortear a representação política e, consequentemente, esvaziando 0 ideal preconizado pelo regime democrático.

Com isso não há um governo do povo, mas de uma minoria que, aproveitando-se da imperfeição da legislação eleitoral, manipula a soberania popular de modo a salvaguardar seus próprios interesses, quais sejam: manter-se longe do alcance da lei e perpetuar-se no poder.

Por outro lado, verifica-se uma forte tendência ao alheamento, pois a população cada vez mais se omite das opiniões e ações que interessam à coletividade, conforme salienta Cecília Pires ${ }^{17}$ :

$\mathrm{Na}$ motivação participativa dos cidadãos, vê-se nos grandes países que monitoram os blocos econômicos (G-8, G-20) uma deliberação de não comprometimento

\footnotetext{
${ }^{16}$ GUÉHENNO, Jean-Marie. O fim da democracia: um ensaio profundo e visionário sobre o próximo milênio. Rio de Janeiro: Bertrand Brasil, 1994, p. 34.

${ }^{17}$ PIRES, Cecilia. Democracia contemporânea: quais impasses? In: AZAMBUJA, Celso Candido de. HELFER, Inácio. Política e liberdade no século XXI. São Leopoldo: Editora Nova Harmonia, 2011, p. 35.
} 
Weidlich, Amanda de Moraes; Schneider, Paulo Henrique. A solidariedade social como instrumento para superação da crise da democracia representativa. Revista Eletrônica Direito e Política, Programa de Pós-Graduação Stricto Sensu em Ciência Jurídica da UNIVALI, Itajaí, v.10, n.4, 30 quadrimestre de 2015. Disponível em: www.univali.br/direitoepolitica - ISSN $1980-7791$.

com qualquer governabilidade, pois nenhum produz no espírito do indivíduo um sentimento de unidade e competência. Esse vazio ético apresenta-se no imaginário social como grande argumento para a não participação.

O descrédito dos representantes perante seus representados e, portanto, a decepção com a classe política, levou ao desinteresse pelo exercício da cidadania e da participação popular. Consequência disso são os altos índices de abstenção dos cidadãos nas eleições e nos mecanismos de consulta popular.

As abismais diferenças entre classes econômicas também contribuem para a crise da democracia, pois, quando se tem fome, não se cogitam dos direitos mais elementares à igualdade, ou mesmo à liberdade, e, portanto, da existência de um regime democrático.

Salienta Antonio Maria Baggio, nesse sentido, que a democracia moderna procurou superar o paradigma da pólis grega, que conferia cidadania apenas ao homem adulto e livre, chegando ao momento de crise atual, em que as diferenças econômicas impõem indagar, novamente, quem são os cidadãos e que vínculo se estabelece entre eles. ${ }^{18}$

Hoje a democracia não é mais ameaçada pelo totalitarismo, representado pelo islamismo ou mesmo pelo comunismo, como se acreditou até pouco tempo atrás. Para Tzvetan Todorov, é o descomedimento, concebido como o oposto da moderação (virtude política por excelência), que verdadeiramente perturba os regimes democráticos. ${ }^{19}$

Já se demonstrou que democracia é composta por diversos elementos e, no momento em que quaisquer deles são isolados e absolutizados, tornam-se inimigos íntimos da democracia: o povo leva ao populismo; a liberdade leva ao ultraliberalismo; e o progresso leva ao messianismo. A ameaça pós-

\footnotetext{
${ }^{18}$ BAGGIO, Antonio Maria. O princípio esquecido: exigências, recursos e definições da fraternidade na política. São Paulo: Cidade Nova, 2009, p.88.

${ }^{19}$ TODOROV, Tzvetan. Os inimigos íntimos da democracia, p. 12-14.
} 
Weidlich, Amanda de Moraes; Schneider, Paulo Henrique. A solidariedade social como instrumento para superação da crise da democracia representativa. Revista Eletrônica Direito e Política, Programa de Pós-Graduação Stricto Sensu em Ciência Jurídica da UNIVALI, Itajaí, v.10, n.4, 30 quadrimestre de 2015. Disponível em: www.univali.br/direitoepolitica - ISSN $1980-7791$.

moderna à democracia é, por assim dizer, interna, e não mais externa. ${ }^{20}$

Isso tanto é verdade que, tomando o exemplo do Brasil, constata-se verdadeira crise de legitimidade do Poder Legislativo, causada pelo distanciamento entre representantes e representados, o qual inviabiliza a análise da compatibilidade entre a vontade popular e a vontade expressada pela maioria Parlamentar. ${ }^{21}$

Há também o notório "mercado" que antecede as votações no Congresso Nacional, pois nenhum projeto de lei é aprovado sem que haja intensa negociação entre os líderes partidários, como se fosse possível barganhar com o interesse público, chegando ao ponto de criar a esdrúxula profissão de "consultor legislativo", eufemismo empregado para designar a atividade de "lobista".

Todos esses elementos indicam indubitavelmente para uma crise da democracia representativa, aqui entendida não como sinônimo de caos e desestruturação, mas como o "processo impulsionado pela perda de identidade de sujeitos ou sistemas que acaba desembocando numa incapacidade de superar obstáculos e cumprir com suas metas estabelecidas" 22 , e que deverá necessariamente impor à democracia uma forma de ressignificação, sob pena de perecimento.

Há quem já tenha decretado o fim das nações e da política e, por consequência, o fim da democracia, como Jean-Marie Guéhenno ${ }^{23}$, entretanto, considerando que qualquer regime democrático é preferível ao totalitarismo, há que se investigar saídas para a crise que assola a democracia representativa pós-moderna, máxime porque as crises sociais

\footnotetext{
${ }^{20}$ TODOROV, Tzvetan. Os inimigos íntimos da democracia. p. 18.

${ }^{21}$ BITTENCOURT, Caroline Müller. DORNELLES, Tiago. A Insuficiência do modelo representativo: a necessária construção de uma democracia efetiva à luz de "novas formas" de participação popular. In: GORCZEVSKI, Clovis. Direitos Humanos e Participação Política. Vol. IV. Porto Alegre: Imprensa Livre, 2013, p. 365.

${ }^{22}$ GUGLIANO, Alfredo Alejandro. A crise política como solução? Uma reflexão desde a perspectiva das democracias participativas. In: Revista Brasileira de Direito Constitucional. n. 3. São Paulo: Editora Método, 2004, p. 342.
}

${ }^{23}$ GUÉHENNO, Jean-Marie. O fim da democracia, p. 31. 
Weidlich, Amanda de Moraes; Schneider, Paulo Henrique. A solidariedade social como instrumento para superação da crise da democracia representativa. Revista Eletrônica Direito e Política, Programa de Pós-Graduação Stricto Sensu em Ciência Jurídica da UNIVALI, Itajaí, v.10, n.4, 30 quadrimestre de 2015. Disponível em: www.univali.br/direitoepolitica - ISSN $1980-7791$.

impulsionam ações tendentes a superá-las e que, ao final, poderão gerar efeitos positivos. ${ }^{24}$

\section{A EVOLUÇÃO DA CONCEPÇÃO DE SOLIDARIEDADE}

As transformações econômicas e sociais ocorridas a partir da segunda metade do século XIX resultaram no surgimento de um novo paradigma social e jurídico, fundado na consciência da vida em comunhão com os semelhantes e na necessidade de auxílio mútuo.

Entretanto, a origem da solidariedade remonta à Antiguidade Clássica, a partir da afirmação de Protágoras, de que "o homem é a medida de todas as coisas", e, portanto, da constatação de que o ser humano é um animal social, sendo a convivência social mais que uma imposição natural da existência, mas uma necessidade para tornar a vida menos custosa e sacrificante ${ }^{25}$.

No cristianismo primitivo, a ideia de solidariedade revestiu-se de contornos jurídicos, pois os juristas romanos empregavam o termo "in solidum" para designar a responsabilidade pelo todo, ou seja, a obrigação que une os devedores a um mesmo credor. ${ }^{26}$

Durante a Idade Média, também denominada "Idade das Trevas", predominou o Teocentrismo, posteriormente substituído pelo Individualismo e pelo Antropocentrismo com o advento do Renascimento, quando o homem passou a ser o destinatário de todo o interesse científico. ${ }^{27}$

Após esse período de esquecimento, a concepção de solidariedade foi retomada na modernidade a partir dos ideais da Revolução Francesa

\footnotetext{
${ }^{24}$ GUGLIANO, Alfredo Alejandro. A crise política como solução? p. 336.

${ }^{25}$ CARDOSO, Alenilton da Silva. Princípio da Solidariedade: o paradigma ético do direito contemporâneo. São Paulo: Editora Juarez de Oliveira, 2010, p. 91.

${ }^{26}$ MORAES, Maria Celina Bodin de. O Princípio da Solidariedade. Disponível em <http://www.idcivil.com.br/pdf/biblioteca9.pdf> Consultado em 08.02.2014.

${ }^{27}$ AVELINO, Pedro Buck. Princípio da Solidariedade: Imbricações Históricas e sua inserção na Constituição de 1988. In: Revista de Direito Constitucional e Internacional. n. 53. São Paulo: Editora Revista dos Tribunais, 2005, p. 238.
} 
Weidlich, Amanda de Moraes; Schneider, Paulo Henrique. A solidariedade social como instrumento para superação da crise da democracia representativa. Revista Eletrônica Direito e Política, Programa de Pós-Graduação Stricto Sensu em Ciência Jurídica da UNIVALI, Itajaí, v.10, n.4, 30 quadrimestre de 2015. Disponível em: www.univali.br/direitoepolitica - ISSN $1980-7791$.

(Liberdade, Igualdade e Fraternidade), quando então se disseminou o dever de prestar ajuda a aqueles que necessitem, confundindo-se os conceitos de solidarismo, caridade e filantropia. ${ }^{28}$

O surgimento do Estado-liberal-capitalista trouxe inegáveis benefícios jurídicos e sociais à humanidade, como, por exemplo, a afirmação dos direitos humanos, mas também fomentou o egoísmo e a miséria, os quais foram agravados com a ideia de Estado mínimo e sua política de não intervenção na vida social. ${ }^{29}$

Com efeito, o século XIX foi pautado pelo individualismo, pela valorização das habilidades pessoais e da criatividade intelectual do homem ${ }^{30}$, e por consequência, pelo enaltecimento do "eu" em detrimento do "nós", condições essas que conduziram à disseminação do egoísmo e fomentaram as já crescentes diferenças sociais.

Daí porque a verdadeira descoberta da solidariedade ocorreu somente no final do século XIX e início do século $X X$, quando a expressão passou a denominar uma nova maneira de pensar a relação entre os indivíduos, a sociedade e o Estado, forjando um discurso ético coerente, diverso da caridade e da filantropia. ${ }^{31}$

Segundo Leon Bourgeois, ao contrário do que se pensava até o início do século $X X$, a solidariedade não se trata de mera variante do terceiro lema Republicano, qual seja, a Fraternidade, mas representa um "quase contrato social", pois o homem nasce em débito com a sociedade: é o preço que paga pela liberdade. ${ }^{32}$

Para o autor citado, o conhecimento das leis de solidariedade destruiu o

\footnotetext{
${ }^{28}$ FARIAS, José Fernando de Castro. A origem do direito de solidariedade. Rio de Janeiro: Renovar, 1998, p. 188.

${ }^{29}$ SILVA, Cleber Demétrio de Oliveira da. O princípio da solidariedade. Disponível em <http://demetrioefonseca.adv.br/site/sites/default/files/artigos/solidariedade.pdf> consultado em 08.02.2014.

${ }^{30}$ MORAES, Maria Celina Bodin de. O princípio da solidariedade.

${ }^{31}$ FARIAS, José Fernando de Castro. A origem do direito de solidariedade, p. 190.

${ }^{32}$ BOURGEOIS, Léon. Solidarieté. Paris: Librairie Armand Colin, 1902, p. 110-111.
} 
Weidlich, Amanda de Moraes; Schneider, Paulo Henrique. A solidariedade social como instrumento para superação da crise da democracia representativa. Revista Eletrônica Direito e Política, Programa de Pós-Graduação Stricto Sensu em Ciência Jurídica da UNIVALI, Itajaí, v.10, n.4, 30 quadrimestre de 2015. Disponível em: www.univali.br/direitoepolitica - ISSN $1980-7791$.

isolamento do homem e estabeleceu um elo natural e moral, que o conecta aos seus antepassados e aos seus descendentes, tornando-o devedor da associação humana. ${ }^{33}$

Émile Durkheim aponta para a existência de diferentes espécies de solidariedade: mecânica e orgânica. A solidariedade mecânica ou por similitudes pressupõe a existência de duas consciências no ser humano: uma diz respeito a sua individualidade, e contém apenas os traços pessoais de cada um; e a outra é comum a toda a sociedade, que se reúne em razão da semelhança de seus integrantes. Essa solidariedade nascida das semelhanças e da coesão social, pois vincula diretamente o indivíduo à sociedade ao partilharem uma consciência comum, Durkheim denominou mecânica ou por similitudes. ${ }^{34}$

A solidariedade orgânica, pelo contrário, pressupõe a personalidade singular do indivíduo e decorre da divisão do trabalho, "é necessário, pois, que a consciência coletiva deixe descoberta uma parte da consciência individual, para que nela se estabeleçam essas funções especiais que ela não pode regulamentar". ${ }^{35}$

"Enquanto na solidariedade mecânica o indivíduo é amarrado diretamente à sociedade, sem nenhum intermediário, na solidariedade orgânica o indivíduo depende da intermediação da sociedade antes de tudo, porque ele é ligado às partes que a compõem", pondera Émile Durkheim. ${ }^{36}$

A solidariedade seria, assim, decorrência de dois fatos sociais distintos: os homens seriam solidários uns com os outros por pertencerem ao mesmo grupo social (solidariedade mecânica ou por similitudes), ou por necessitarem da troca de serviços recíprocos para a satisfação de seus

\footnotetext{
${ }^{33}$ BOURGEOIS, Leon. Solidarieté, p. 111.

${ }^{34}$ DURKHEIM, Émile. Da divisão do trabalho social. São Paulo: Martins Fontes, 2013, p. 79.

35 DURKHEIM, Émile. Da divisão do trabalho social, p. 108.

${ }^{36}$ FARIAS, José Fernando de Castro. A origem do direito de solidariedade, p. 217.
} 
Weidlich, Amanda de Moraes; Schneider, Paulo Henrique. A solidariedade social como instrumento para superação da crise da democracia representativa. Revista Eletrônica Direito e Política, Programa de Pós-Graduação Stricto Sensu em Ciência Jurídica da UNIVALI, Itajaí, v.10, n.4, 30 quadrimestre de 2015. Disponível em: www.univali.br/direitoepolitica - ISSN $1980-7791$.

anseios (solidariedade orgânica ou pela divisão do trabalho). ${ }^{37}$

No âmbito jurídico, o solidarismo foi abordado por Léon Duguit, que constatou o paradoxo existente entre a individualidade e a necessidade do ser humano viver em sociedade. Com efeito, embora o homem anseie por sua individualidade, ele tem ciência de que a existência em sociedade é um fato e uma necessidade e, portanto, independe de sua vontade ${ }^{38}$.

De acordo com o pensamento do jurista francês, a solidariedade é o que mantém a sociedade e, por consequência, a humanidade, de modo a impor ao homem uma regra de conduta consubstanciada numa dupla obrigação: de um lado, não praticar atos que atentem contra a solidariedade social e, de outro, realizar toda atividade tendente a desenvolvê-la. ${ }^{39}$

A partir das noções preconizadas pelo solidarismo, Georges Gurvitch discorreu sobre o "direito social", ou seja, sobre a construção de um direito desvinculado dos indivíduos que tutela, mas atrelado aos seus respectivos grupos sociais.

Segundo Gurvitch, o direito social trata-se de

um direito autônomo de comunhão, integrando de uma forma objetiva cada totalidade ativa real, que encarna um valor positivo atemporal. Este direito advém diretamente do 'todo' em questão, para regular-lhe a vida interna, independentemente do fato que este 'todo' seja organizado ou não. O direito de comunhão faz participar o 'todo' de uma forma imediata na relação jurídica que dele resulta, sem transformar este 'todo' em um sujeito distinto dos seus membros. ${ }^{40}$

Ou seja, a proposta de direito social apresentada por Gurvitch revela vários pontos de contato com as concepções solidárias, pois, em comum, propõem

\footnotetext{
${ }^{37}$ DUGUIT, Léon. Fundamentos do Direito. São Paulo: Ícone, 1996, p. 23.

${ }^{38}$ DUGUIT, Léon. Fundamentos do Direito. p. 21.

${ }^{39}$ DUGUIT, Léon. Fundamentos do Direito. p. 25.

${ }^{40}$ GURVITCH, Georges. Apud MORAIS, José Luis Bolzan de. A ideia de Direito Social: 0 Pluralismo Jurídico de Georges Gurvitch. Porto Alegre: Livraria do Advogado, 1997, p. 37.
} 
Weidlich, Amanda de Moraes; Schneider, Paulo Henrique. A solidariedade social como instrumento para superação da crise da democracia representativa. Revista Eletrônica Direito e Política, Programa de Pós-Graduação Stricto Sensu em Ciência Jurídica da UNIVALI, Itajaí, v.10, n.4, 30 quadrimestre de 2015. Disponível em: www.univali.br/direitoepolitica - ISSN $1980-7791$.

a superação do individualismo, resultando, por consequência, num direito de comunhão, um direito de coletividades, que nasce do próprio grupo que rege. ${ }^{41}$

A solidariedade se contrapõe, assim, à indiferença, responsabilizando o indivíduo para com seus semelhantes, "colocando-o numa perspectiva de responsabilidade com os hipossuficientes, os cidadãos de outros países e até mesmo os que nascerão nas futuras gerações". ${ }^{42}$

No Brasil, o solidarismo não passou despercebido por Rui Barbosa, que, a partir das ideias dos pensadores europeus, também atrelou à solidariedade a noção de paradigma ético do direito:

Já não se vê na sociedade um mero agregado, uma justaposição de unidades individuais, acasteladas cada qual no seu direito intratável, mas uma entidade naturalmente orgânica, em que a esfera do indivíduo tem por limites inevitáveis, de todos os lados, a coletividade. O direito vai cedendo à moral, o indivíduo à associação, o egoísmo à solidariedade humana. ${ }^{43}$

O ideal solidário foi reafirmado pelo constituinte de 1988, que inseriu, dentre os objetivos da República Federativa do Brasil, constantes do art. 30 da Magna Carta, a construção de uma sociedade livre, justa e solidária.

Não se trata de mera declaração de intenções, a inserção da solidariedade como princípio e objetivo da República Federativa do Brasil, inaugura uma nova ordem jurídica que expressa um comando, exigindo do legislador, dos juristas e especialmente dos cidadãos, respectivamente, a elaboração e a interpretação das leis de acordo com o discurso solidário, bem como a prática de ações solidárias.

A solidariedade também é o elemento norteador do Princípio da Capacidade Contributiva, constante do art. 145, $1^{a}$, da Constituição Federal, ao

\footnotetext{
${ }^{41}$ MORAIS, José Luis Bolzan de. A ideia de Direito Social: O Pluralismo Jurídico de Georges Gurvitch. Porto Alegre: Livraria do Advogado, 1997, p. 39.

${ }^{42}$ CARDOSO, Alenilton da Silva. Princípio da Solidariedade: o paradigma ético do direito contemporâneo. São Paulo: Juarez de Oliveira, 2010, p. 106.

${ }^{43}$ BARBOSA, Rui. Apud FARIAS, José Fernando de Castro. A origem do direito de solidariedade. Rio de Janeiro: Renovar, 1998, p. 192.
} 
Weidlich, Amanda de Moraes; Schneider, Paulo Henrique. A solidariedade social como instrumento para superação da crise da democracia representativa. Revista Eletrônica Direito e Política, Programa de Pós-Graduação Stricto Sensu em Ciência Jurídica da UNIVALI, Itajaí, v.10, n.4, 30 quadrimestre de 2015. Disponível em: www.univali.br/direitoepolitica - ISSN $1980-7791$.

determinar a graduação dos impostos de acordo com a capacidade econômica de cada contribuinte e, especialmente, da Seguridade Social prevista a partir do art. 194 da Magna Carta, que prevê a cooperação entre o Estado e a Sociedade no sentido de assegurar a uma universalidade de pessoas os direitos básicos a uma vida digna. ${ }^{44}$

Mais que a simples noção de caridade apresentada pela Revolução Francesa, constata-se que o solidarismo representa a superação do egoísmo rumo à construção de uma sociedade equânime, constituindo verdadeiro paradigma ético e valor jurídico do Estado que pretende ser Democrático de Direito, o que será aprofundado a seguir.

\section{O RESGATE DA SOLIDARIEDADE SOCIAL COMO INSTRUMENTO PARA SUPERAÇÃO DA CRISE DA DEMOCRACIA REPRESENTATIVA}

Os fenômenos da mundialização e da globalização, aliados ao crescimento desenfreado do capitalismo, derrubaram fronteiras e encurtaram distâncias, fazendo com que a humanidade vislumbrasse a possibilidade de existência do que Edgar Morin denominou de "sociedade-mundo"45. Era de se esperar, portanto, que a mitigação das diferenças fomentasse a integração entre os povos e favorecesse a formação de uma identidade e de uma consciência coletiva.

Porém, a realidade não correspondeu a essas expectativas, pelo contrário, o que se verifica hoje é a exacerbação do "eu" e, por consequência, a disseminação do individualismo e do egocentrismo, que, aliados à máxima liberdade e aos demais elementos indicados no primeiro tópico deste ensaio, contribuíram para a crise democrática atual.

Com efeito, ao mesmo tempo que unificou, a globalização também desagregou, contribuindo para a corrupção, o egocentrismo, o

\footnotetext{
${ }^{44}$ AVELINO, Pedro Buck. Princípio da Solidariedade, p. 238.

${ }^{45}$ MORIN, Edgar. La via para el futuro de la humanidad. Tradução de Núria Petit Tontseré. Barcelona: Paidós, 2011, p. 21
} 
Weidlich, Amanda de Moraes; Schneider, Paulo Henrique. A solidariedade social como instrumento para superação da crise da democracia representativa. Revista Eletrônica Direito e Política, Programa de Pós-Graduação Stricto Sensu em Ciência Jurídica da UNIVALI, Itajaí, v.10, n.4, 30 quadrimestre de 2015. Disponível em: www.univali.br/direitoepolitica - ISSN $1980-7791$.

individualismo, a indiferença e a destruição da solidariedade tradicional, ao reunir interesses em conflito e ao apregoar o modo de vida ocidental, desconsiderando as especificidades locais. ${ }^{46}$

Consequências do desenvolvimento, a especialização e a individualização fizeram com que a sociedade passasse a se organizar de modo compartimentado, impedindo a assunção de responsabilidades conjuntas e, por conseguinte, levando à supressão da concepção de solidariedade.

A banalização da miséria e a indiferença perante o sofrimento alheio demonstram que, assim como a democracia, a sociedade também está doente, pois, segundo Alenilton da Silva Cardoso, "a civilização humana chegou num estágio em que o seu elemento central perdeu o significado", concluindo que "o ser humano passou a ser nada". ${ }^{47}$

Disso se constata que a democracia carece de um sustentáculo ético, que paute da vida dos cidadãos e de seus representantes, ligando-os por um vínculo político, jurídico e, especialmente, fraterno, ético e solidário, de modo a reconciliar o regime democrático com os nobres objetivos que propõe.

Inúmeros são os caminhos a serem percorridos para a reabilitação da democracia, passando por medidas políticas, de civilização, de demografia, ecológicas, sanitárias, econômicas, de redução da pobreza e das desigualdades e de desburocratização.

Pode-se destacar, porém, que, nos tempos atuais, mais do que nunca, a construção de uma sociedade democrática passa pelo conteúdo das expressões "viver o outro-em-mim", e "viver o eu-nos-outros"48, que exprimem justamente as ideias de interdependência e de reconhecimento e harmonização das diferenças numa sociedade pluralista.

\footnotetext{
${ }^{46}$ MORIN, Edgar. La via para el futuro de la humanidad, p. 25-26.

${ }^{47}$ CARDOSO, Alenilton da Silva. Princípio da Solidariedade, p. 104.

${ }^{48}$ MIGLIORIN, Cezar apud MEDEIROS, Fernanda Luiza Fontoura de; e PETTERLE, Selma Rodrigues. Biodiversidade: Uso Inclusivo e Sustentável do Ambiente. In: Revista de Direito Ambiental e Urbanístico. V. 1 (ago./set. 2005). Porto Alegre: Magister, 2005, p.23.
} 
Weidlich, Amanda de Moraes; Schneider, Paulo Henrique. A solidariedade social como instrumento para superação da crise da democracia representativa. Revista Eletrônica Direito e Política, Programa de Pós-Graduação Stricto Sensu em Ciência Jurídica da UNIVALI, Itajaí, v.10, n.4, 30 quadrimestre de 2015. Disponível em: www.univali.br/direitoepolitica - ISSN $1980-7791$.

Ao aclamar a vontade da maioria, a democracia implica a existência de uma minoria dissonante, do que se constata que o regime democrático pressupõe o pluralismo e, portanto, a existência de uma "igualdade dissenssual"49. Partindo dessa premissa, a tradicional concepção de democracia (de igualdade de direitos e poder de todos) é alargada para abranger o direito à diferença e à vida com dignidade, que requerem, necessariamente, a mitigação do antropocentrismo.

Ou seja, a constituição de um regime verdadeiramente democrático exige o reconhecimento e a afirmação das diferenças, o que passa pela superação do "eu" egoístico e da coisificação das relações humanas. Com efeito, a redução das desigualdades e a construção de uma sociedade justa, segura e democrática, requer um reposicionamento ético e o reconhecimento dos direitos do próximo, o que é possível com o fortalecimento da solidariedade. ${ }^{50}$

O indivíduo não se basta, sua existência está intimamente ligada à vida em sociedade, a qual requer sacrifícios mútuos, capazes de estabelecer laços fortes e duradouros entre os seres humanos. Esse sentimento de dependência faz com que o homem se acostume a se ver como parte inafastável de um todo: a sociedade. Por isso, toda sociedade é uma sociedade moral. ${ }^{51}$

Consoante já salientado alhures, o indivíduo é egoísta por natureza, mas têm ciência de que seus anseios somente poderão ser atendidos na vida em comunidade, logo a existência em sociedade é um fato primitivo e humano, e que, a toda evidência, independe da vontade humana. ${ }^{52}$

A solidariedade assume, assim, um conteúdo ético que reúne os membros de uma sociedade a partir da constatação de que dependem uns dos outros para existirem e para viverem com dignidade, contrapondo-se à indiferença

\footnotetext{
${ }^{49}$ MIGLIORIN, Cezar apud MEDEIROS, Fernanda Luiza Fontoura de; e PETTERLE, Selma Rodrigues. Biodiversidade, p.23.

${ }^{50}$ CARDOSO, Alenilton da Silva. Princípio da Solidariedade, p. 105.

${ }^{51}$ DURKHEIM, Émile. Da divisão do trabalho social, p. 118.

${ }^{52}$ DUGUIT, Léon. Fundamentos do Direito, p. 21.
} 
Weidlich, Amanda de Moraes; Schneider, Paulo Henrique. A solidariedade social como instrumento para superação da crise da democracia representativa. Revista Eletrônica Direito e Política, Programa de Pós-Graduação Stricto Sensu em Ciência Jurídica da UNIVALI, Itajaí, v.10, n.4, 30 quadrimestre de 2015. Disponível em: www.univali.br/direitoepolitica - ISSN $1980-7791$.

e ao egoísmo exacerbado. A solidariedade social é, por assim dizer, o laço que une as individualidades numa mesma comunidade. ${ }^{53}$

Cuida-se, portanto, do estabelecimento de um novo paradigma para definir a atividade do Estado, mais sólido que a noção de soberania popular, pois, de certo modo, a solidariedade supera a bipolarização que existia entre o liberalismo e o marxismo, ao buscar, pela via da máxima liberdade, os objetivos de equidade almejados pelo socialismo. ${ }^{54}$

Segundo José Fernando de Castro Farias ${ }^{55}$

Pretende-se, então, dar uma nova legitimidade ao Estado. Através da solidariedade, a democracia se põe a serviço da sociedade e o Estado encontra a sua missão social. Mas a passagem da soberania à solidariedade, como fundamento do Estado e do direito não pode ser simplesmente reduzida a uma passagem do político ao social, pois não podemos esquecer a dimensão ética e moral do solidarismo e suas consequências na ideia de laço social.

A concepção da solidariedade como paradigma ético não acarreta somente alterações em relação à atuação estatal, mas principalmente estabelece um novo liame moral entre os seres humanos, resgatando os sentimentos de cooperação e alteridade, e, por isso mesmo, fomentando a ideia de democracia enquanto direito de todos.

Não é por outra razão, aliás, que Edgar Morin sugere o implemento de uma democracia participativa, que revitalize os espíritos de comunidade, de solidariedade e de responsabilidade, como "remédio" aos males da democracia representativa. Para tanto, o sociólogo e filósofo acredita que cargos importantes da administração pública (juízes, professores, administradores, etc) sejam ocupados por pessoas escolhidas também de acordo com seu sentimento de justiça e equidade e pela sua aptidão para a benevolência, de modo a possibilitar a concepção de uma "Terra Pátria" a

53 DUGUIT, Léon. Fundamentos do Direito, p. 22.

${ }^{54}$ FARIAS, José Fernando de Castro. A origem do direito de solidariedade, p. 193.

${ }^{55}$ FARIAS, José Fernando de Castro. A origem do direito de solidariedade, p. 193. 
Weidlich, Amanda de Moraes; Schneider, Paulo Henrique. A solidariedade social como instrumento para superação da crise da democracia representativa. Revista Eletrônica Direito e Política, Programa de Pós-Graduação Stricto Sensu em Ciência Jurídica da UNIVALI, Itajaí, v.10, n.4, 30 quadrimestre de 2015. Disponível em: www.univali.br/direitoepolitica - ISSN $1980-7791$.

partir do resgate da solidariedade. ${ }^{56}$

Ora, se a democracia se constitui pelo reconhecimento e pela harmonização das diferenças e, portanto, pela valorização de cada indivíduo que integra o grupo, forçoso concluir que a interdependência entre os membros de uma comunidade, em que as condições de vida de uns interferem diretamente no bem estar coletivo, exige a adoção de uma rede solidária de ajuda mútua.

O bem comum e, portanto, a democracia, exigem a tomada de decisões que harmonizem as diferenças havidas no seio de uma comunidade, sejam elas econômicas, culturas, religiosas, dentre outras.

Da mesma forma, a participação democrática também pressupõe a compreensão das diversidades, impondo uma relação de solidária e de interdependência entre os cidadãos, sob pena de fomentar a intolerância, conforme assevera Antonio Maria Baggio ${ }^{57}$

\begin{abstract}
Participar significa, hoje, sobretudo - e muito mais que em qualquer outra época histórica - , tornar-se capaz de interagir, de dialogar, de compreender os outros e suas diversidades, num espaço de cidadania culturalmente não-homogêneo. [...] É preciso, hoje, compreender o outro, entrar, em certo sentido, na profundidade cultural do outro, para evitar justamente que a diversidade gere suspeitas, medos, mecanismos de defesa, agressividade.
\end{abstract}

O modelo de democracia representativa tradicional atém-se ao aspecto formal do processo democrático, pois se encontra fundado no estabelecimento de regras ao procedimento eleitoral, olvidando-se do conteúdo substancial da democracia.

Fundada na solidariedade social e, portanto, no reconhecimento da igualdade e da interdependência entre os indivíduos, essa democracia

\footnotetext{
${ }^{56}$ MORIN, Edgar. La via para el futuro de la humanidad, p. 63-64.

${ }^{57}$ BAGGIO, Antonio Maria. O princípio esquecido, p.96-97.
} 
Weidlich, Amanda de Moraes; Schneider, Paulo Henrique. A solidariedade social como instrumento para superação da crise da democracia representativa. Revista Eletrônica Direito e Política, Programa de Pós-Graduação Stricto Sensu em Ciência Jurídica da UNIVALI, Itajaí, v.10, n.4, 30 quadrimestre de 2015. Disponível em: www.univali.br/direitoepolitica - ISSN $1980-7791$.

participativa que se propõe surge como alternativa viável à democracia tradicional, mediante o estabelecimento de canais de interlocução diretos entre governantes e governados, bem como a implementação de mecanismos coletivos de gestão dos recursos e da administração pública. ${ }^{58}$

Ou seja, essa maior participação dos cidadãos na tomada das decisões de um Estado, que poderá contribuir para a superação da crise que assola o modelo democrático representativo tradicional, é viável com o reconhecimento da solidariedade social como o laço que reúne as individualidades forjando a sociedade, e portanto, como verdadeiro paradigma ético da democracia.

\section{CONSIDERAÇÕES FINAIS}

A democracia representativa tradicional passa por um momento de crise, a exigir a busca de alternativas viáveis à sua reabilitação, a fim de evitar o crescente descrédito às suas instituições e permitir o implemento das promessas democráticas.

Conforme visto, o conceito de democracia representativa foi-se alterando com o passar do tempo, até chegar à moderna concepção, que basicamente exprime os seguintes elementos: 1) poder exercido pelo povo; 2) representantes legitimamente eleitos; 3) regras eletivas previamente estabelecidas; 4) observância e respeito aos direitos e garantias fundamentais dos cidadãos; e 5) a existência de uma sociedade livre em que prepondera a influência popular.

Entretanto a democracia representativa nos moldes em que é concebida atualmente tornou-se insuficiente à construção de uma sociedade livre, justa e fraterna, na medida em que vivencia o alheamento cada vez maior de seus cidadãos, decepcionados com seus representantes.

Sugeriu-se, com isso, o estabelecimento de um novo paradigma ético à

\footnotetext{
${ }^{58}$ GUGLIANO, Alfredo Alejandro. A crise política como solução? p. 344.
} 
Weidlich, Amanda de Moraes; Schneider, Paulo Henrique. A solidariedade social como instrumento para superação da crise da democracia representativa. Revista Eletrônica Direito e Política, Programa de Pós-Graduação Stricto Sensu em Ciência Jurídica da UNIVALI, Itajaí, v.10, n.4, 30 quadrimestre de 2015. Disponível em: www.univali.br/direitoepolitica - ISSN $1980-7791$.

democracia, fundado no resgate do sentimento de solidariedade entre os cidadãos, reunindo-os por um vínculo fraterno, a partir da superação do individualismo e da constatação da interdependência entre os seres humanos.

Com efeito, ao deixar de lado o antropocentrismo e, portanto, ao vivenciar a alteridade, o cidadão passa a verdadeiramente participar do regime democrático, envolvendo-se direta e pessoalmente com as questões que importam ao Estado e, principalmente, que interessam aos seus semelhantes.

\section{REFERÊNCIAS DAS FONTES CITADAS}

ARENDT, Hanna. A Condição Humana. São Paulo: Forense Universitária, 1981.

BARROSO, José Durão. Democracia. In: POLIS Enciclopédia Verbo da Sociedade e do Estado:Antropologia, Direito, Economia, Ciência Política. São Paulo: Verbo, 1987. v. 2.

BITTENCOURT, Caroline Müller. DORNELLES, Tiago. A Insuficiência do modelo representativo: a necessária construção de uma democracia efetiva à luz de "novas formas" de participação popular. In: GORCZEVSKI, Clovis. Direitos Humanos e Participação Política. Vol. IV. Porto Alegre: Imprensa Livre, 2013.

BOBBIO, Norberto. Dicionário de Política.12. ed. Brasília: UnB, 2004, p.319.

BOBBIO, Norberto. O Futuro da Democracia. Uma defesa das regras do jogo. 2. ed. Tradução Marco Aurélio Nogueira. Rio de Janeiro: Paz e Terra, 1999.

BOBBIO, Norberto. Liberalismo e Democracia. Tradução: Marco Aurélio Nogueira. São Paulo: Brasiliense, 2005.

BOURGEOIS, Léon. Solidarieté. Paris: Librairie Armand Colin, 1902.

CARDOSO, Alenilton da Silva. Princípio da Solidariedade: o paradigma ético do direito contemporâneo. São Paulo: Editora Juarez de Oliveira, 2010. 
Weidlich, Amanda de Moraes; Schneider, Paulo Henrique. A solidariedade social como instrumento para superação da crise da democracia representativa. Revista Eletrônica Direito e Política, Programa de Pós-Graduação Stricto Sensu em Ciência Jurídica da UNIVALI, Itajaí, v.10, n.4, 30 quadrimestre de 2015. Disponível em: www.univali.br/direitoepolitica - ISSN $1980-7791$.

DUGUIT, Léon. Fundamentos do Direito. São Paulo: Ícone, 1996.

DURKHEIM, Émile. Da Divisão do Trabalho Social. São Paulo: Martins Fontes, 2013.

FARIAS, José Fernando de Castro. A origem do direito de solidariedade. Rio de Janeiro: Renovar, 1998.

GUÉHENNO, Jean-Marie. O fim da democracia: um ensaio profundo e visionário sobre o próximo milênio. Rio de Janeiro: Bertrand Brasil, 1994.

GUGLIANO, Alfredo Alejandro. A crise política como solução? Uma reflexão desde a perspectiva das democracias participativas. In: Revista Brasileira de Direito Constitucional. n. 3. São Paulo: Editora Método, 2004, p. 335-349.

GURVITCH, GEORGES. Apud MORAIS, José Luis Bolzan de. A ideia de Direito Social: O Pluralismo Jurídico de Georges Gurvitch. Porto Alegre: Livraria do Advogado, 1997.

LINCOLN, Abraham. 0 discurso de Gettysburg. Disponível em <http://www.oabsp.org.br/institucional/grandes-causas/o-discurso-degettysburg>. Acesso em 03 fevereiro 2014.

MIGLIORIN, Cezar apud MEDEIROS, Fernanda Luiza Fontoura de; e PETTERLE, Selma Rodrigues. Biodiversidade: Uso Inclusivo e Sustentável do Ambiente. In: Revista de Direito Ambiental e Urbanístico. V. 1 (ago./set. 2005). Porto Alegre: Magister, 2005.

MORAES, Maria Celina Bodin de. O Princípio da Solidariedade. Disponível em <http://www.idcivil.com.br/pdf/biblioteca9.pdf> Consultado em 08.02.2014.

MORAIS, José Luis Bolzan de. A ideia de Direito Social: O Pluralismo Jurídico de Georges Gurvitch. Porto Alegre: Livraria do Advogado, 1997.

MORIN, Edgar. La via para el futuro de la humanidad. Tradución de Núria Petit Tontseré. Barcelona: Paidós, 2011.

PANIZA, Alexandre de Lima. Democracia e Contratualismo nas concepções de Hobbes e Rousseau: uma abordagem histórica. In: Revista Brasileira de Direito Constitucional. n. 3. São Paulo: Editora Método, 2004, p. 249-267.

PIRES, Cecilia. Democracia contemporânea: quais impasses? In: AZAMBUJA, Celso Candido de. HELFER, Inácio. Política e liberdade no século XXI. São Leopoldo: Editora Nova Harmonia, 2011.

SILVA, Cleber Demétrio de Oliveira da. O princípio da solidariedade. 
Weidlich, Amanda de Moraes; Schneider, Paulo Henrique. A solidariedade social como instrumento para superação da crise da democracia representativa. Revista Eletrônica Direito e Política, Programa de Pós-Graduação Stricto Sensu em Ciência Jurídica da UNIVALI, Itajaí, v.10, n.4, 30 quadrimestre de 2015. Disponível em: www.univali.br/direitoepolitica - ISSN $1980-7791$.

Disponível em <http://demetrioefonseca.adv.br/site/sites/default/files/artigos/solidariedad e.pdf > consultado em 08.02.2014.

TODOROV, Tzvetan. Os inimigos íntimos da democracia. Tradução Joana Angélica d'Avila Melo. São Paulo: Companhia das Letras, 2012.

Submetido em: Setembro/2015

Aprovado em: Novembro/2015 